\title{
Neck-specific exercises with internet-based support compared to neck-specific exercises at a physiotherapy clinic for chronic whiplash-associated disorders: study protocol of a randomized controlled multicentre trial
}

\author{
Anneli Peolsson ${ }^{1 *}$ (D), Maria Landén Ludvigsson ${ }^{1,2}$ and Gunnel Peterson ${ }^{1,3}$
}

\begin{abstract}
Background: Globally, neck pain is the fourth most common condition associated with longer periods of living with disability. Annually, approximately $0.3 \%$ of the population of Western countries undergo whiplash trauma, and half of those individuals will develop chronic problems with high costs for the individual and society. Evidence for chronic whiplash-associated disorders (WAD) treatment is scarce, though neck-specific training at a physiotherapy clinic twice a week for 12 weeks has demonstrated good results. More efficient, flexible rehabilitation with reduced waiting times and lower costs is needed, ideally replacing lengthy on-site treatment series by healthcare providers. Internet-based care has been shown to be a viable alternative for a variety of diseases and interventions, but studies are lacking on Internet-based interventions for individuals with chronic neck problems. The aim of the trial described here is to compare the effects of an Internet-based neck-specific exercise programme to the same exercises performed at a physiotherapy clinic in regards to self-reported and clinical measures, as well as cost-effectiveness.
\end{abstract}

Methods: This prospective, randomized controlled trial will involve 140 participants. Measurements will be made at baseline, 3 months (end of treatment), and 15 months (12 months after end of intervention) and will include ratings of pain, disability, satisfaction with care, work ability, quality of life, and cost-effectiveness.

Discussion: The study results may contribute to the development of a more effective rehabilitation, flexible and equal care, shorter waiting times, increased availability, and lower costs for healthcare and society.

Trial registration: ClinicalTrials.gov Protocol ID: NCT03022812, initial release 12/20/2016.

Keywords: Whiplash injury, Neck, Spine, Chronic, Physiotherapy, Rehabilitation, Exercise therapy, Randomized, Follow-up study, Outcome

\footnotetext{
* Correspondence: Anneli.Peolsson@liu.se

${ }^{1}$ Department of Medical and Health Sciences, Physiotherapy, Linköping

University, Sandbäcksg. 7,58183 Linköping, Sweden

Full list of author information is available at the end of the article
} 


\section{Background}

\section{Epidemiology, aetiology, cost, and symptoms}

Of 301 classified diseases, neck pain is fourth in the "Global Burden of Disease Study" [1], which evaluated years lived with disability. A common reason for neck pain is a whiplash injury, with an annual reported incidence of approximately $0.3 \%[2,3]$. Whiplash trauma is an indirect neck trauma in which acceleration, deceleration, and the compressive forces of the head are transmitted to the cervical spine, exposing it to high mechanical forces during the whiplash movement. Of those who are injured, roughly half experience chronic ( $\geq 6$ months) WAD [4-6]. Whiplash injury is graded in five degrees according to the most used classification, the modified Quebec Task Force (QTF) [7]. Common symptoms in WAD in addition to neck pain are headaches, radiculopathy, dizziness, balance problems, mental illness, sleep disorders, lower quality of life, low general health, and a decreased ability to work [2, 4, 6, 8-11], leading to very high individual and social costs [2-4].

\section{The knowledge gap}

Strong evidence is lacking on how chronic WAD should be treated [12-16]. Although exercise has the best quality evidence $[12,13,16]$, previous studies of exercise in chronic WAD have shown somewhat disperse results. Considering the chronicity of the population, large group differences cannot be expected, but smaller clinically relevant improvements can be very valuable. In WAD grade $1-2$ (grade $1=$ no physical findings; grade 2 = local neck findings), simple advice is equally as effective as a more intense and comprehensive physiotherapy exercise programme [17]. However, in WAD grade 2-3 (grade 3 = grade $2+$ neurological findings), neck-specific exercise is more effective than prescribed physical activity 2 years post-treatment [10, 11, 18-21]. One reason for the different results may be the different WAD grades, as WAD grade 3 has been associated with treatment success $[18,19]$. It is also reasonable that people without physical signs of WAD and only self-reported pain (grade 1) will do just as well with advice. Another explanation may be that different kinds of exercise programmes have been used that often included only elements of exercises targeting the neck muscles $[17,22,23]$ or improved aerobic capacity without neck-specific exercises [24]. The main outcome also varies among studies. Information on the effect of neck-specific exercise programmes consisting of both neuromuscular and neck muscle endurance exercises for both ventral and dorsal neck muscles is scarce, as are studies involving patients with higher WAD grades (grade 3) [18, 19]. Studies regarding physical exercise in individuals with chronic pain, WAD and WAD-related headaches included [15, 25-27] has been identified as representing priority knowledge gaps.

The currently planned study would help fill these gaps and be important for future rehabilitation, with benefits for both individuals and society. For individuals with chronic WAD, studies on Internet-based care are lacking. Similarly, no study has included specific neck exercises distributed through the Internet for individuals with neck problems.

\section{Why is it important to exercise the neck muscles?}

The term whiplash does not communicate the actual pathology, only the mechanism of injury. Although the aetiology and diagnosis regarding WAD are unclear, some of the symptoms can be related to various cervical spine structures, such as the muscles, ligaments, facet joints, discs, and nerves [28-33], leading, for example, to inflammation, fat infiltration, muscle fibre conversion, lower range of neck motion, disturbed neuromuscular control, and impaired neck muscle function [34-45]. Indications also exist for disturbed muscle function predisposing an individual to recurrent problems [46].

The muscle function of the cervical spine is very important for stability, eye-hand coordination, postural control, and interactions between the vision and vestibular systems for good balance and to avoid dizziness, pain, and disability $[47,48]$. Deteriorated muscle function does not seem to be restored automatically without specific neck exercises [34, 46, 49-51]. For individuals with mechanical neck pain, including WAD, evidence suggests that neck exercise is effective [14, 52-55], and it is recommended in clinical guidelines [56]. However, most intervention studies involve acute WAD and research addressing neckspecific exercises for both ventral and dorsal neck muscles, consisting of both neuromuscular and endurance exercises, in chronic WAD is scarce. Only Ludvigsson et al., Landén Ludvigsson et al. [18, 19], and Peolsson et al. [57] included individuals with more severe WAD (grade 3) to compare three exercise interventions: neck-specific exercise, neck-specific exercise combined with behavioural therapy, and prescription of general physical activity. When the interventions were completed after 3 months of training ( 2 times/week, total of 24 times), the individuals who practised neck-specific exercises improved, with no significant differences between the two neckspecific groups, and the general physical activity group remained almost unchanged or worse [10, 11, 18-20]. In another study, neck-specific exercise for chronic WAD was compared to being on the waiting list for 3 months [57]. The neck-specific exercise group improved as the waiting list group deteriorated in most variables [57]. Neck-specific exercise is recommended for individuals with chronic WAD [16], but further research is needed, especially for those with chronic WAD and greater disability.

\section{E-health}

The healthcare system is undergoing challenges of the future; care needs to be developed, improved, and made more efficient while also offering increased availability 
and controlled costs. Patients of working age can also have difficulty taking time off from work to access the provided healthcare. It is also important to gain access to care despite geographical distances. New ways of offering healthcare need to be developed to increase availability and patient adherence, shorten waiting times, and reduce costs, especially in the case of longer treatment series, as with exercise treatment at a physiotherapy clinic for those with chronic problems. Internet-based treatment may also develop and strengthen the patient's own resources for greater autonomy and the ability to conduct long-term self-care [58]. Internet-based healthcare has been increasing as technology evolves and more individuals have access to a computer/tablet/smartphone and the Internet [59]. This kind of treatment delivery could also facilitate the implementation and deployment of therapy shown to be effective in research studies $[10,11,18-20]$. Treatment delivery via the Internet has good, equal, or better efficacy than face-to-face treatment with the caregiver for a number of diseases, including exercises for individuals with stress incontinence, low back pain, heart disease, rheumatoid arthritis, and after knee arthroplasty, as well as for chronic pain [60-65]. People report preferring Internetbased delivery because of the increased flexibility and convenience $[66,67]$. However, disadvantages of relying only on Internet-based care include insufficient support, information, and understanding. A few visits to the caregiver combined with Internet-based support has been shown to be preferable [68].

Regarding people with neck problems, including WAD, only one study has incorporated Internet-based care [69]. Bring et al. [69] included individuals with acute WAD grade 1 and 2 and reported that a behavioural programme of direct encounters with the healthcare provider and an Internet-based behavioural programme both led to less pain-related dysfunction, and both were better than the standard treatment (i.e., a pamphlet). However, for individuals with chronic WAD, including those with more severe degrees of WAD (grade 3), studies on Internet-based care are lacking. No study has included specific neck exercises distributed through the Internet for individuals with neck problems. Furthermore, studies evaluating the comparative costs of these modes of rehabilitation are also lacking.

Although previous studies on chronic $\operatorname{WAD}(10,11$, $18-21,57)$ reported that 12 weeks of neck-specific exercise is effective and cost-effective, it requires quite a bit of resources. Thus, it is important to investigate whether the same effect can be achieved if delivered in a more cost-effective way with fewer physiotherapist visits and an Internet support.

\section{Aim}

The aim of the trial is to compare the effects of an Internet-based neck-specific exercise programme (NSEIT) with the same exercises (NSE) performed at a physiotherapy clinic in regards to self-reported and clinical measures, as well as cost-effectiveness. Further objectives are to identify factors associated with the outcome following exercise regarding pain and disability.

Hypothesis: Internet-based neck-specific exercises with four visits to the physiotherapist will be non-inferior to neck-specific exercises at a physiotherapy clinic twice a week for 12 weeks (i.e., treatment NSEIT is not inferior to NSE) at 3- and 15-month follow-ups, and NSEIT yields lower economic costs for society than NSE.

\section{Methods/design \\ Design}

This is an experimental, longitudinal, prospective, multicentre, randomized controlled trial (RCT) with two parallel treatment arms conducted according to a detailed protocol decided on before recruitment started (ClinicalTrials.gov Protocol ID: NCT03022812). Physiotherapistled neck-specific exercise previously shown to be effective for the current population $[18,19]$ constitutes the control treatment for the new Internet-based neck-specific exercise treatment. A total of 140 people (70 in each group) are expected to be included, mainly by self-selection after advertisements. Independent physiotherapists in primary care will distribute the treatment. Due to the nature of the study, neither participants nor treating therapists can be blinded. To be un-biased to data the project manager will not be involved in the data collection. The physical measurements will instead be performed by independent testleaders/specially trained, skilled, physiotherapists blinded to randomization. Data collection in the form of questionnaires and tests of physical neck-related function occurs at baseline (before randomization) and after 3 (end of physiotherapy rehabilitation) months and 15 months (1 year post-intervention) (Table 1$)$. The study has been approved by the regional ethics committee in Linköping, Sweden (Dnr 2016/135-31; 2016/526-32; 2017/45-32). Recruitment started April 6, 2017 (Fig. 1) and is planned to continue until the 140 participants have been recruited.

\section{Study population}

Individuals with a whiplash injury from a traffic accident with a four-wheeled motor vehicle at least 6 months ago but less than 5 years ago will be included after written and oral informed consent if they have chronic neck problems corresponding to WAD grades 2-3 [7] verified by clinical examination and have not participated in a neck-specific exercise programme in a previous research study $[18,19]$. Additional inclusion criteria are: average estimated pain in the last week at least $20 \mathrm{~mm}$ on the visual analogue scale (VAS) [70], neck disability of more than $20 \%$ on the Neck Disability Index (NDI) [71], working age (18-63 years), daily access to a computer/tablet/ 
Table 1 Schedule of enrolment, interventions, and assessments

\begin{tabular}{|c|c|c|c|c|c|c|}
\hline \multirow[b]{4}{*}{ TIMEPOINT ${ }^{c}$} & \multicolumn{6}{|c|}{ STUDY PERIOD } \\
\hline & \multirow{3}{*}{$\begin{array}{l}\text { Enrolment } \\
0\end{array}$} & \multirow{3}{*}{$\begin{array}{l}\text { Allocation } \\
0\end{array}$} & \multicolumn{3}{|c|}{ Post-allocation } & \multirow{3}{*}{$\begin{array}{l}\text { Close-out } \\
t_{x}\end{array}$} \\
\hline & & & $t_{1}$ & $t_{2}$ & $t_{3}$ & \\
\hline & & & & & & \\
\hline \multicolumn{7}{|l|}{ ENROLMENT } \\
\hline Eligibility screen & $x$ & & & & & \\
\hline Informed consent & $x$ & & & & & \\
\hline Allocation & & $x$ & & & & \\
\hline \multicolumn{7}{|l|}{ INTERVENTIONS ${ }^{a}$} \\
\hline NSE & & & $x$ & $x$ & $x$ & \\
\hline NSEIT & & & $x$ & $x$ & $x$ & \\
\hline \multicolumn{7}{|l|}{ ASSESSMENTS ${ }^{b}$} \\
\hline Demographic data & $x$ & & $x$ & & & \\
\hline $\begin{array}{l}\text { Self-reported } \\
\text { outcomes } \\
\text { (questionnaires) }\end{array}$ & & & $x$ & $x$ & $x$ & $x$ \\
\hline Clinical outcome & & & $x$ & $x$ & $x$ & $x$ \\
\hline
\end{tabular}

${ }^{\mathrm{a}} \mathrm{NSE}=12$ weeks of neck-specific exercise at physiotherapy clinic, NSEIT = 12 weeks of neck-specific exercise with 4 appointments at physiotherapy clinic + Internet support

${ }^{\mathrm{b}} \mathrm{Q}$ uestionnaires on various aspects of disability, pain, psychosocial factors, etc., including the main outcome the Neck Disability Index. Clinical outcomes including neck muscle endurance, range of motion, neurological tests, etc. $\mathrm{c}_{\mathrm{t}_{1}}$ = baseline, $\mathrm{t}_{2}=3$-month follow-up, $\mathrm{t}_{3}=15$-month follow-up, $\mathrm{t}_{\mathrm{x}}=1$ 15-month follow-up (12 months post-intervention)

smart phone and Internet, time to follow the treatment programme, and neck symptoms within the first week after the injury (i.e., neck pain, neck stiffness, or cervical radiculopathy).

Individuals with any of the following signs of head injury at the time of whiplash injury will be excluded: loss of consciousness, amnesia before or after the injury, altered mental status (e.g., confusion, disorientation), focal neurological changes (changes in smell and taste). Additional exclusion criteria are previous fractures or dislocation of the cervical column; known or suspected serious physical pathology included myelopathy, spinal tumours, spinal infection, or ongoing malignancy; previous severe neck problems that resulted in sick leave for more than a month in the year before the current whiplash injury; surgery in the cervical column; generalized or more dominant pain elsewhere in the body; other illness/injury that may prevent full participation in the study and/or in which neck exercises are contraindicated; inability to understand and write in Swedish; diagnosed severe mental illness, such as psychosis, schizophrenia, personality disorders; or current alcohol and drug abuse.

\section{Recruitment and randomization}

Information on the study will be provided by healthcare providers, advertising in newspapers, posters, social media, and the university's website. Patients may also be recruited consecutively as they seek treatment for their problems in primary healthcare. Interested patients will contact the research team (experienced physiotherapists) through the website. After completing a small survey on the website, a project team member will perform a telephone interview and ask about the patient's medical history. As a last step an appointment for a physical examination is made to ensure the criteria for study participation are met. If the study criteria are met and written and oral informed consent obtained (distributed by the independent test leader), the patient will fill out a questionnaire (baseline data) and undergo physical measurements of neck-related function. Baseline measurements must be completed for inclusion.

A computerized block randomization list stratified by gender (conducted by a statistician and allocated by a project team member) will be used for randomization into two groups. Both groups will perform neck-specific exercises for 12 weeks: NSE (exercises at a physiotherapy clinic 2 times/week) or NSEIT (Internet-based support exercises in combination with four visits to the physiotherapist). The randomization will be performed by an independent researcher not otherwise involved in any of the tests or treatments. The researcher sends an opaque envelope containing the name and contact details of the patient and information about the randomization group to the treating physiotherapist, who calls the patient in to a new clinical examination (according to law) before treatment can start. The physiotherapists (in primary healthcare or working privately in out-patient care) will receive oral and written information and a day of practical training by the project leader. The treating physiotherapist is also able to consult with the project managers at any time if necessary. An exercise diary is maintained by patients in both groups and the number of care contacts recorded by the physiotherapist. A total of 140 participants with chronic WAD grades 2 and 3 will be recruited (70 per group).

\section{Intervention}

In the NSE group, participants will get an explanation and justification for the exercise consisting of basic information about the musculoskeletal anatomy of the neck relevant to the exercises given by the physiotherapist in order to motivate the patient and help make them feel safe and reassured. Elements of a behavioural approach are also included, such as neurophysiological and neurobiological education and strategies for dealing with neck pain relapse. The patients undergo a 12-week training programme with a physiotherapist 2 days/week (total 24 times). Exercises are chosen from a clear and written frame of exercises. The training includes exercises for the deep neck muscles, continuing with the endurance 


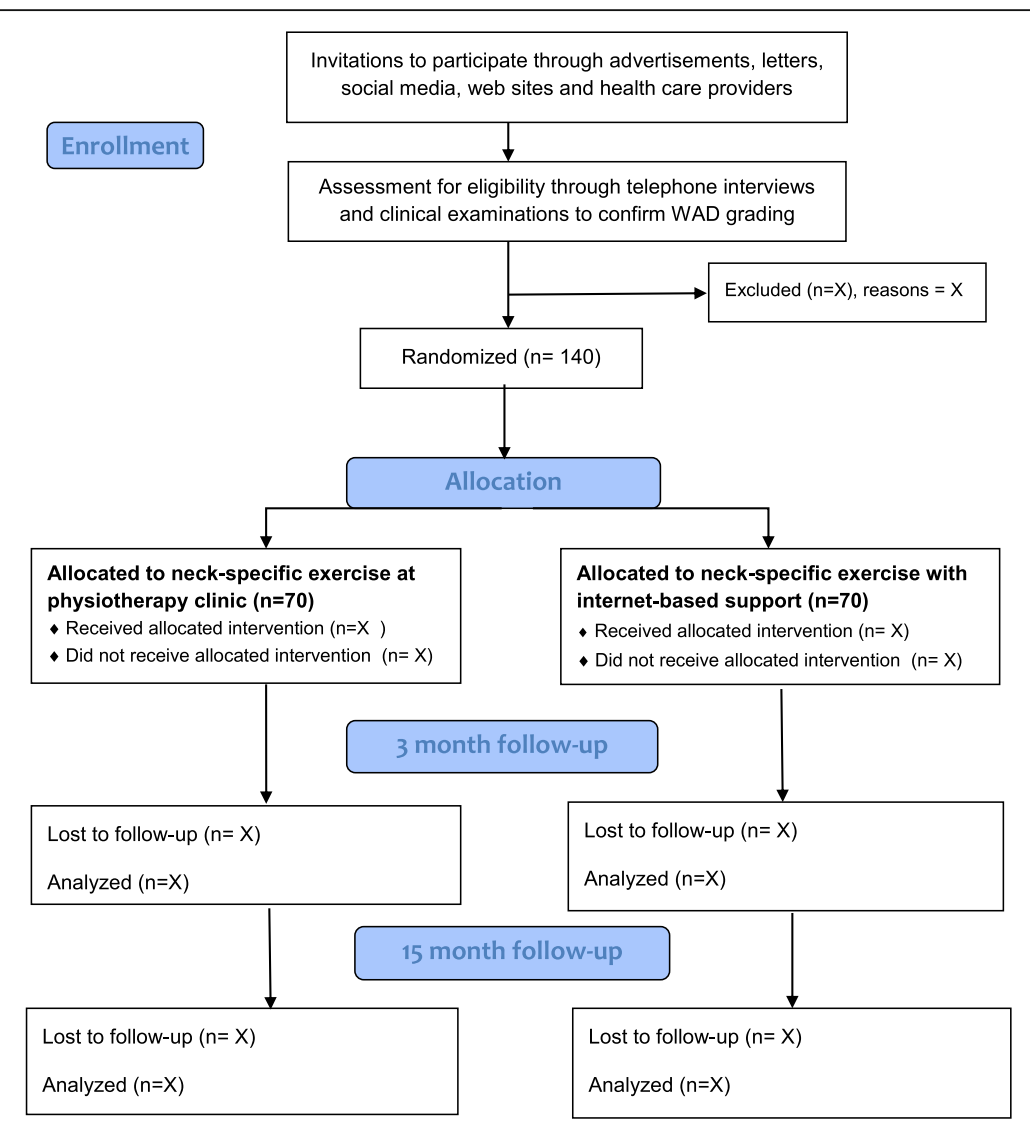

Fig. 1 CONSORT Flow Diagram for Neck-specific exercises with Internet-based support compared to exercises performed in a longer series at a physiotherapy clinic: a prospective randomized multicentre study of people with chronic whiplash-associated disorders

training of neck and shoulder muscles. The exercises are individually adjusted according to the individual's physical conditions and progressively increased in severity and dose. Exercise-related pain provocation is not accepted. The individual may also perform exercises at home. At the end of the treatment period, the participants are encouraged to continue practising on their own. The first visit to the physiotherapist is estimated to take $60 \mathrm{~min}$ and the others $30 \mathrm{~min}$. The exercises have been used with good results in a previous RCT $[18,19]$ (DOI https://doi.org/10.3384/report.diva-113,865).

In the NSEIT group, participants will receive the same information and training programmes as the NSE group, but with four visits to the physiotherapist instead of 24 . Exercises are introduced, progressed, and followed up to ensure correct performance. The exercises are performed and most of the information given with the help of Internet support outside the healthcare system. Photos and videos of the exercises, information, and answers to frequently asked questions are available on the Internet (Web-based system designed by the project leaders at the university). Patients can contact his/her physiotherapist if necessary. The first visit to the physiotherapist is estimated to take $60 \mathrm{~min}$ and the other visits
$30 \mathrm{~min}$. The time required for training is the same as in group A, but without the patient having to go to the physiotherapy clinic. The Internet programme was developed together with technicians, clinicians, and researchers and has been tested by people with chronic whiplash without any negative comments, except one person who had firewalls that needed to be adjusted on her/his work computer. Technicians are available to assist the participants should any technical difficulties arise, and patients receive follow-up questions regarding the Web support at the end of the intervention. The participants will learn the exercises and get information and support at the physiotherapy visits.

\section{Variables and measurements}

All questionnaires will be answered electronically through a website. Participants will receive a disposable code e-mailed by a project team member to $\log$ in to the system (not the first survey before study inclusion). The electronic questionnaire cannot be submitted if the core outcomes are not answered. If a participant does not answer the questionnaire after two reminders (1.5 weeks after it is due and after another 1.5 weeks), a project team member not involved in the randomization 
procedure will phone the patient to collect the core outcomes of the NDI and pain variables. The Web-based questionnaire has been tested by both the project group and people with chronic neck pain (including WAD) and adjusted thereafter. Clinical measurements will be performed by test leaders in primary care settings in the different counties involved in the study.

Background data that will be collected include age, sex, family status, symptom duration, former healthcare, education, occupational classification ("Standard for Swedish work classification" SSY code [72]), post-traumatic stress reactions using the Post-traumatic Stress Disorder checklist (PCL-S) [73, 74], and the expectation of future treatment.

The primary outcome measure that will be collected is neck-specific function as measured by the NDI [71] (for example of the data collection form, please see http:// www.aaos.org/uploadedFiles/NDI.pdf).

Secondary outcome measures that will be collected include neck-related function as measured by the Whiplash Disability Questionnaire [75-77] and patient-specific functional scale [78]; pain intensity in the neck, head, and arm (0-100 mm VAS) [70]; distribution of pain (Pain Sketch app) [79]; frequency of pain as measured by a 5 -grade scale and use of pain medications; dizziness/balance according to the Dizziness Handicap Inventory (DHI) [80] and VAS [70]; headache according to a VAS [70] and the Headache Impact Test (HIT-6) [81]; cognitive ability according to the Cognitive Failures Questionnaire (CFQ) [82]; catastrophizing according to the Pain Catastrophizing Scale [83]; confidence in ability (Self-Efficacy Scale) [84]; operating fear according to the Fear Avoidance Beliefs Questionnaire (FABQ) [85, 86]; depression and anxiety measured with the Hospital Anxiety and Depression Scale (HAD) [87]; self-rated work ability measured by the Work Ability Index (WAI) [88-90]; sick days recorded (number of days/part of days, and dates of periods of sick days according to the Social Insurance Agency MIDAS register); income according to the Swedish tax office; health-related quality of life (EuroQuol) [91]; Global Rating of Change Scale [92]; requirements-effort support in the workplace according to the Effort Reward Imbalance [93]; ergonomics and how work is perceived; sickness presence (Stanford presenteeism scale) [94, 95]; self-assessment of sick-leave and data from the social security office; expectations and satisfaction with healthcare fulfilled by Cherkin Symptoms Satisfaction [96] and Patient Enablement Instrument [97] and questions of how they perceived study participation; level of physical activity measured with two questions about daily activities and sports [98, 99]; and adherence to treatment according to an exercise diary. Selfassessed care consumption and data obtained from the county council's healthcare database or similar will be used in the cost-effectiveness analysis, and self-assessed consumption of analgesic drugs and data from the drug registry will also be collected. Two reminders will be send to participants who do not answer the questionnaires.

Tests that will be performed by the test leader [99-106], an independent physiotherapist, include active and passive range of neck motion [100], neck muscle endurance [99], cervical flexion-rotation test [101], palpation for segmental tenderness in the upper cervical spine [102], sensorimotor control [103], balance standing on one leg with eyes closed [104], hand strength [105], and neurology related to the neck, such as sensibility (touch and pin prick), upper limb reflexes, segmental identification muscle strength, upper limb tension test, Spurling's test, and traction test [106].

In addition to being an outcome measure, physical examinations were used in combination with medical history for WAD grading [7] and potential additional diagnosis of cervicogenic headache [107]. Any important harms or unintended side effects in each group will be collected by the test leaders.

\section{Ethical considerations}

The study was approved by the regional ethical review board in Linköping, Sweden. A previous clinical study relating to three different exercise interventions for long-term problems after whiplash injury [10, 11, 18-20] demonstrated good efficacy of neck-specific exercise performed in a primary healthcare setting. Current treatment is according to the best scientific evidence, and exercises used in the present study have been used in daily clinical practice for decades in the rehabilitation of various forms of neck pain. All of the physical tests are well-established and used both clinically and in previous research studies, are non-invasive, and do not cause danger or harm to the individual except for some risk of muscle soreness. Participants are included after a thorough clinical examination and provide signed informed consent. The exercises are adjusted individually. Participants are insured by the Swedish Legal, Financial, and Administrative Services Agency (Kammarkollegiet).

Login is required to fill in Internet-based surveys and to gain access to the Internet-based exercise programme. If the effect of the Internet-based exercise programme is good, the researchers' intention is that it be used in clinical practice. People with long-term problems often have little access to assessments and treatments, as more acute conditions are often prioritized in the healthcare system. Both groups in the present study get active care that is expected to increase work ability. The benefit is deemed to be great, and there are no commercial interests.

The results will be presented at the group level, and no connection to the individual person can be made. All data are anonymous and subject to the official health secrets act. 


\section{Statistical analysis}

Sample size and power regarding group differences were calculated by a statistician (non-inferiority trial, an assumption that treatment $\mathrm{B}$ is not inferior to $\mathrm{A}$ ) in the software PASS (version 13.0.8) based on the primary outcome NDI [71]. To detect a clinically relevant improvement of $7 \%$ in the NDI, 47 participants are needed in each group for $80 \%$ power. For non-inferiority tests, the significance level was set to $5 \%(p>0.05)$, which corresponds to the one-sided confidence interval $(95 \% \mathrm{CI})$. To be improved, both groups need a 7\% increase in NDI (mean or median value depending on data) $[71,108,109]$. A non-inferiority border of less than $7 \%$ was chosen for mean NDI scores because it is on the border of what would be considered a clinically important effect $[71,108]$. In addition, for secondary outcomes, the mean/median score will be on the border of what would be considered a clinically important effect for each measurement. The 95\% CI will be examined and, if the upper limit of the interval is less than the chosen border value, non-inferiority of NSEIT to NSE will be concluded. For background data, and if appropriate after the noninferiority test, a two-sided superiority test will be performed with a significance level of 5\%. These values are based on the standard deviation (SD 13.4) of the NDI in a previous study of neck-specific exercises in individuals with chronic WAD grade 2 and $3[18,19]$. To ensure that enough people are in each group after drop-outs, for prediction analyses, and the opportunity for subgroup analyses, 70 participants will be included in each group.

Analyses will be performed in collaboration with a statistician using parametric or non-parametric statistics depending on the type of data and whether the analysis is between groups or over time. Analyses will be performed primarily on an intention-to-treat basis (as individuals being randomized into the two groups) and secondarily on a per protocol basis (counted on individuals who fulfilled the programme for at least $50 \%$ ). Imputation methods may be used when deemed to have additional value. Subgroup analyses of age, gender, WAD grade, headache, and dizziness may possibly be performed. Database monitoring will be performed by the project leaders and statisticians involved after study completion, independent of sponsors and competing interests. The project leaders and collaborating statisticians and researchers will have access to the final trial dataset (after the project leaders' allowances).

Background data will be evaluated by descriptive statistics and differences in baseline data determined using t-test (mean and standard deviation) or non-parametric test where appropriate. A linear mixed model or general linear mixed model (GLMM) may be used depending on the data. NDI will be evaluated as a dependent variable with independent fixed factors time (baseline, 3 months, and 15 months after start of intervention) and group (A and $\mathrm{B}$ ). If the non-inferiority of $\mathrm{B}$ to $\mathrm{A}$ is concluded based on the $95 \% \mathrm{CI}$, a test of the superiority of B to A will be performed as suggested by Lessafre [110]. Costeffectiveness will be calculated from both a societal and healthcare perspective using incremental cost-effectiveness ratios (ICERs) based on the EQ-5D for QALY calculations. The variation in response to intervention (heterogeneity of treatment effect) will be evaluated using regression analysis.

\section{Timetable}

The project started April 6, 2017. The inclusion period is estimated to be finalized after approximately 2 years. Thereafter, participants will be followed for another 15 months. Ethical approval has been obtained.

\section{Plan for the implementation and dissemination of research results}

Several factors can hinder or facilitate the introduction of scientific knowledge into practical or organizational activities. These factors may be related to the individual caregiver, the social context of the caregiving environment, or the organizational context. A survey of these factors will provide direction for implementation and a basis for selecting the best implementation strategy. Educational sessions are commonly used to implement new treatment strategies. Previous research of such sessions has established that the inclusion of interactive components makes them more successful. Other important determinants of success are innovation characteristics (e.g., neck-specific training), adopter characteristics, implementation strategies, and contextual factors. The long-term goals of this study are to optimize treatment plans for patients, which will improve the rate at which they can return to work and participate in society.

\section{Discussion}

The clinical advantages of the project are great because patients with long-standing WAD experience disability at great personal and social cost. Thus, an urgent need exists to expand our knowledge of rehabilitation. Areas to be explored include disability associated with WAD and the effect of Internet-based physiotherapy treatment outcomes. The present study will help provide evidence of treatment efficacy for patients with WAD. The longterm goals of this study are to optimize treatment plans for patients, which will improve the rate at which they can return to work and participate in society.

\section{Trial limitations}

This is a multicentre study involving multiple intervening therapists, which offers less control, and the performance of the intended interventions may be compromised. However, to minimize this risk, the physiotherapists will be trained by the project leaders and have time to practise 
the standardized interventions in preparation for the study. Furthermore, a multicentre study may be more generalizable and enhance implementation. Participants need to have access to a computer/smartphone/tablet and an Internet connection. Most people, even those in the older age groups, have access to such equipment nowadays [59]. To be able to answer the questionnaires and understand the Web-based programme, participants need to speak and read Swedish. However, providing that the results of the Web-based programme will be equally good, it can be translated into other languages to include a non-Swedish-speaking population.

\section{Acknowledgements}

The authors wish to thank the County Councils and physiotherapists that will be involved.

\section{Funding}

This study is supported by funding from the regional Center for Clinical Research and the County Council of Östergötland, Centre for Clinical Research Sörmland at Uppsala University, the Medical Research Council of Southeast Sweden, the Uppsala-Örebro Regional Research Council, and the County Council of Sörmland. We will be applying for additional funding. The study is the author's own work and there is no conflict of interest. Sponsors may communicate trial results on governmental or county council websites.

\section{Availability of data and materials}

Not applicable as there is no existing data yet.

\section{Author's contributions}

Scientific idea: AP; Project planning: AP, GP, and MLL; Manuscript writing: AP; Manuscript revision: AP, GP, and MLL; Funding: GP and MLL with support from AP. All authors approved the final manuscript.

\section{Ethics approval and consent to participate}

The study has been approved by the regional ethics committee in Linköping, Sweden (Dnr 2016/135-31; 2016/526-32; 2017/45-32). Participants are included after a thorough clinical examination and provide signed informed consent.

\section{Consent for publication}

Not applicable.

\section{Competing interests}

The authors declare that they have no competing interests.

\section{Publisher's Note}

Springer Nature remains neutral with regard to jurisdictional claims in published maps and institutional affiliations.

\section{Author details}

'Department of Medical and Health Sciences, Physiotherapy, Linköping University, Sandbäcksg. 7, 58183 Linköping, Sweden. ${ }^{2}$ Department of Rehabilitation and Department of Medical and Health Sciences, Rehab Väst, County Council of Östergötland, Linköping University, Linköping, Sweden. ${ }^{3}$ Centre for Clinical Research Sörmland, Uppsala University, Eskilstuna, Sweden.

Received: 11 April 2017 Accepted: 15 November 2017

Published online: 12 December 2017

\section{References}

1. GBD 2013 Risk Factors Collaborators, Forouzanfar MH, Alexander L, Anderson HR, et al. Global, regional, and national incidence, prevalence, and years lived with disability for 301 acute and chronic diseases and injuries in 188 countries, 1990-2013: a systematic analysis for the global burden of disease study 2013. Lancet. 2015;386:743-800.
2. Holm LW, Carroll LJ, Cassidy JD, Hogg-Johnson S, Côté P, Guzman J, et al. The burden and determinants of neck pain in whiplash-associated disorders after traffic collisions: results of the bone and joint decade 2000-2010 task force on neck pain and its associated disorders. Spine. 2008;33(Suppl):52-S59.

3. The Whiplash Commission Final Report. 2005. http://www. whiplashkommissionen.se/www.whiplashkommissionen.se/pdf/WK_ finalreport.pdf. Accessed 4 Mar 2012.

4. Leth-Petersen S, Rotger GP. Long-term labour-market performance of whiplash claimants. J Health Econ. 2009;28:996-1011.

5. Rebbeck T, Sindhusake D, Cameron ID, Rubin G, Feyer A-M, Walsh J, et al. A prospective cohort study of health outcomes following whiplash associated disorders in an Australian population. Inj Prev. 2006;12:93-8.

6. Carroll L, Holm L, Hogg-Johnson S, Cote P, Cassidy D, Haldeman S, et al. Course and prognostic factors for neck pain in whiplash-associated disorders (WAD). Results of the bone and joint decade 20002010 task force on neck pain and its associated disorders. Spine. 2008;33:583-92.

7. Spitzer WO, Skovron ML, Salmi LR, Cassidy JD, Duranceau J, Suissa S, et al. Scientific monograph of the Quebec task force on whiplashassociated disorders: redefining "whiplash" and its management. Spine. 1995;20(Suppl):1-73.

8. Tournier C, Hours M, Charnay P, Chossegros L, Tardy H. Five years after the accident, whiplash casualties still have poorer quality of life in the physical domain than other mildly injured casualties: analysis of the ESPARR cohort. BMC Public Health. 2015:16:13.

9. Agnew L, Johnston V, Landén Ludvigsson M, Peterson G, Overmeer T, Johansson $\mathrm{G}$, et al. Factors associated with work ability in patients with chronic whiplash-associated disorder grade II-III: A cross-sectional analysis. J Rehabil Med. 2015;47:546-51.

10. Overmeer T, Peterson G, Landén Ludvigsson M, Peolsson A. The effect of neck-specific exercise with or without a behavioral approach on psychological factors in chronic whiplash-associated disorders: a randomized controlled trial with a 2-year follow-up. Medicine. 2016;95:e4430.

11. Treleaven J, Peterson G, Ludvigsson ML, Kammerlind AS, Peolsson A. Balance, dizziness and proprioception in patients with chronic whiplash associated disorders complaining of dizziness: a prospective randomized study comparing three exercise programs. Man Ther. 2016;22:122-30.

12. Teasell RW, McClure JA, Walton D, Pretty J, Salter K, Meyer M, et al. A research synthesis of therapeutic interventions for whiplash-associated disorder: part 1- overview and summary. Pain Res Manag. 2010;15:287-94.

13. Teasell RW, McClure JA, Walton D, Pretty J, Salter K, Meyer M, et al. A research synthesis of therapeutic interventions for whiplash-associated disorder (WAD): part 4 - noninvasive interventions for chronic WAD. Pain Res Manag. 2010;15:313-22.

14. Gross A, Paquin JP, Dupont G, Blanchette S, Lalonde P, Cristie T. Exercises for mechanical neck disorders: a Cochrane review update. Man Ther. 2016:24:25-45.

15. Varatharajan S, Ferguson B, Chrobak K, Shergill Y, Côté P, Wong JJ, et al. Are non-invasive interventions effective for the management of headaches associated with neck pain? An update of the bone and joint decade task force on neck pain and its associated disorders by the Ontario protocol for traffic injury management (OPTIMa) collaboration. Eur Spine J. 2016;25:1971-99.

16. Rebeck $T$. The role of exercise and patient education in the noninvasive management of whiplash. J Orthop Sport Phys Ther. 2017:47:481-91.

17. Michaleff ZA, Maher CG, Lin CW, Rebbeck T, Jull G, Latimer J. Comprehensive physiotherapy exercise programme or advice for chronic whiplash (PROMISE): a pragmatic randomised controlled trial. Lancet. 2014; 384:133-41.

18. Ludvigsson ML, Peterson $G$, O'Leary $\mathrm{S}$, et al. The effect of neck-specific exercise with, or without a behavioral approach, on pain, disability and selfefficacy in chronic whiplash-associated disorders: a randomized clinical trial. Clin J Pain. 2015;31:294-303.

19. Landén Ludvigsson M, Peterson G, Dedering A, Peolsson A. One- and twoyear follow-up of a randomized trial of neckspecific exercise with or without a behavioural approach compared with prescription of physical activity in chronic whiplash. J Rehabil Med. 2016;48:56-64.

20. Ardern CL, Peterson G, Ludvigsson ML, Peolsson A. Satisfaction with the outcome of physical therapist-prescribed exercise in chronic whiplashassociated disorders: secondary analysis of a randomized clinical trial. J Orthop Sports Phys Ther. 2016;46:640-9. 
21. Landén Ludvigsson M, Peolsson A, Peterson G, Dedering $\AA$, Johansson G, Bernfort L. Cost-effectiveness of neck-specific exercise with or without a behavioral approach versus physical activity prescription in the treatment of chronic whiplash-associated disorders: analyses of a randomized clinical trial. Medicine. 2017;96:e7274

22. Jull G, Sterling M, Kenardy J, Beller E. Does the presence of sensory hypersensitivity influence outcomes of physical rehabilitation for chronic whiplash?-a preliminary RCT. Pain. 2007;129:28-34.

23. Seferiadis A, Ohlin P, Billhult A, Gunnarsson R. Basic body awareness therapy or exercise therapy for the treatment of chronic whiplash associated disorders: a randomized comparative clinical trial. Disabil Rehabil. 2016;38:442-51

24. Stewart MJ, Maher CG, Refshauge KM, Herbert RD, Bogduk N, Nicholas M. Randomized controlled trial of exercise for chronic whiplash-associated disorders. Pain. 2007;128:59-68.

25. Swedish Council on Health Technology Assessment (SBU). Back pain, Neck pain. An evidence based review. (In Swedish) (Ont i ryggen, ont i nacken: en evidensbaserad kunskapssammanställning). Stockholm: SB Offsett AB, 2000. $\mathrm{Nr}$ 145/2, chapter 14-17.

26. NHS -Evidence from the UK Database of Uncertainties about the Effects of Treatments (DUETs). https://www.evidence.nhs.uk/duets?resID=412800\&tabID= 297\&returnUrl=Search\%3Fpa\%3D16\%26ps\%3D30\%26q\%3Dexercise\%2B benefits\&q=exercise+benefits.

27. NHS Evidence from the UK Database of Uncertainties about the Effects of Treatments (DUETs). https://cks.nice.org.uk/neck-pain-whiplash-injury.

28. Pettersson K, Kärrholm J, Toolanen G, Hildingsson C. Decreased width of the spinal canal in patients with chronic symptoms after whiplash injury. Spine. 1995;20:1664-7.

29. Taylor J, Taylor M. Cervical spine injuries: an autopsy study of 109 blunt injuries. J Musculoskeletal Pain. 1996:4:61-79.

30. Lord SM, Barnsley L, Wallis BJ, Bogduk N. Chronic cervical zygapophysial joint pain after whiplash. A placebo-controlled prevalence study. Spine. 1996;21:1737-44.

31. Pettersson K, Hildingsson C, Toolanen G, Fagerlund M, Björnebrink J. DisC pathology after whiplash injury: a prospective magnetic resonance imaging and clinical investigation. Spine. 1997;22:283-7.

32. Brault JR, Siegmund GP, Wheeler JB. Cervical muscle response during whiplash: evidence of a lengthening muscle contraction. Clin Biomech (Bristol, Avon). 2000;15:426-35.

33. Svensson MY, Boström O, Davidsson J, Hansson HA, Håland Y, Lövsund $P$, Suneson A, Säljö A. Neck injuries in car collisions: a review covering a possible injury mechanism and the development of a new rear-impact dummy. Accid Anal Prev. 2000;32:167-75.

34. Uhlig Y, Weber BR, Grob D, Muntener M. Fiber composition and fibre transmissions in neck muscles of patients with dysfunction of the cervical spine. J Orthop Res. 1995;13:240-9.

35. Linnman C, Appel L, Fredrikson M, Gordh T, Söderlund A, Långström B, Engler H. Elevated [11C]-D-deprenyl uptake in chronic whiplash associated disorder suggests persistent musculoskeletal inflammation. PlosOne. 2011;6:e19182.

36. Schomacher J, Farina D, Lindstroem R, Falla D. Chronic trauma-induced neck pain impairs the neural control of the deep semispinalis cervicis muscle. Clin Neurophysiol. 2012;123:1403-8.

37. Elliott JM. Are there implications for morphological changes in neck muscles after whiplash injury? Spine. 2011;36(Suppl):205-10.

38. Elliott JM, Courtney DM, Rademaker A, Pinto D, Sterling MM, Parrish TB. The rapid and progressive degeneration of the cervical Multifidus in whiplash: an MRI study of fatty infiltration. Spine. 2015;40:E694-700.

39. Peterson GE, Landén Ludvigsson MH, O'Leary SP, Dedering ÅM, Wallman T, Jönsson Ml, et al. The effect of 3 different exercise approaches on neck muscle endurance, kinesiophobia, exercise compliance, and patient satisfaction in chronic whiplash. J Manip Physiol Ther. 2015;38:465-76.

40. Peterson G, Nilsson D, Trygg J, Falla D, Dedering $\AA$, Wallman T, et al. Novel insights into the interplay between ventral neck muscles in individuals with whiplash-associated disorders. Sci Rep. 2015;5:15289.

41. Karlsson A, Leinhard OD, Åslund U, West J, Romu T, Smedby Ö, et al. An investigation of fat infiltration of the Multifidus muscle in patients with severe neck symptoms associated with chronic whiplash-associated disorder. J Orthop Sports Phys Ther. 2016;46:886-93.

42. Peolsson A, Peterson G, Trygg J, Nilsson D. Multivariate analysis of ultrasound-recorded dorsal strain sequences: Investigation of dynamic neck extensions in women with chronic whiplash associated disorders. Sci Rep. 2016;6:30415.

43. Landén Ludvigsson M, Peterson G, Jull G, Trygg J, Peolsson A. Mechanical properties of the trapezius during scapular elevation in people with chronic whiplash associated disorders-A case-control ultrasound speckle tracking analysis. Man Ther. 2016;21:177-82.

44. Elliott JM, Dewald PA, Walton DM, Hornby TG, Parrish TB. Mechanism underlying chronic whiplash: contributions from direct spinal cord injury. Pain Med. 2014;15:1938-44.

45. Peolsson A, Ludvigsson ML, Wibault J, Dedering A, Peterson G. Function in patients with cervical radiculopathy or chronic whiplash-associated disorders compared with healthy volunteers. J Manip Physiol Ther. 2014;37:211-8.

46. Hides JA, Jull GA, Richardson CA. Long-term effects of specific stabilizing exercises for first-episode low back pain. Spine. 2001;26:E243-8.

47. Treleaven J. Dizziness, unsteadiness, visual disturbances, and postural control: implications for the transition to chronic symptoms after a whiplash trauma. Spine. 2011;36(Suppl):211-7.

48. MCPartland JM, Brodeur RR, Hallgren RC. Chronic neck pain, standing balance, and suboccipital muscle atrophy-a pilot study. J Manip Physiol Ther. 1997;20:24-9.

49. Farina D, Arendt-Nielsen L, Merletti R, Graven-Nielsen T. Effect of experimental muscle pain on motor unit firing rate and conduction velocity. J Neurophysiol. 2004;91:1250-9.

50. Falla $D$, Jull $G$, Hodges $P$, Vicenzino $B$. An endurance-strength training regime is effective in reducing myoelectric manifestations of cervical flexor muscle fatigue in females with chronic neck pain. Clin Neurophysiol. 2006;117:828-37.

51. Falla D, O'Leary S, Farina D, Jull G. The change in deep cervical flexor activity after training is associated with the degree of pain reduction in patients with chronic neck pain. Clin J Pain. 2012;28:628-34.

52. Sarig-Bahat $\mathrm{H}$. Evidence for exercise therapy in mechanical neck disorders. Man Ther. 2003;8:10-20.

53. Kay TM, Gross A, Goldsmith C, Santaguida PL, Hiving J, Bronfort G et al. Exercises for mechanical neck disorders. Cochrane Database Syst Rev. 2005; 20;(3):CD004250.

54. Gross AR, Goldsmith C, Hoving JL, Haines T, Peloso P, Aker P, et al. Conservative management of mechanical neck disorders: a systematic review. J Rheumatol. 2007;34:1083-102.

55. Miller J, Gross A, D'Sylva J, Burnie SJ, Goldsmith CH, Graham N et al. manual therapy and exercise for neck pain: a systematic review. Man Ther 2010;15:334-354

56. Wong JJ, Côté P, Shearer HM, Carroll $\sqcup$, Yu H, Varatharajan S, et al. Clinical practice guidelines for the management of conditions related to traffic collisions: a systematic review by the OPTIMa collaboration. Disabil Rehabil. 2015:37:471-89.

57. Peolsson A, Landén Ludvigsson M, Tigerfors AM, Peterson G. Effects of neckspecific exercises compared to waiting list for individuals with chronic whiplash-associated disorders: a prospective, randomized controlled study. Arch Phys Med Rehabil. 2016;97:189-95.

58. Kipping S, Stuckey MI, Hernandez A, Nguyen T, Riahi S. A web-based patient portal for mental health care: benefits evaluation. J Med Internet Res. 2016;18:e294.

59. Fox CS, Hwang SJ, Nieto K, Valentino M, Mutalik K, Massaro JM, et al. Digital connectedness in the Framingham heart study. J Am Heart Assoc. 2016;5: e003193.

60. Cuijpers $P$, van Straten A, Andersson G. Internet-administered cognitive behavior therapy for health problems: a systematic review. J Behav Med. 2008;31:169-77.

61. Sjöström M, Umefjord G, Stenlund H, Carlbring P, Andersson G, Samuelsson E. Internet-based treatment of stress urinary incontinence: a randomised controlled study with focus on pelvic floor muscle training. BJU Int. 2013; 112:362-72.

62. Revenäs Å, Opava C, Ahlén H, Brusewitz M, Pettersson S, Åsenlöf P. Mobile internet service for self-management of physical activity in people with rheumatoid arthritis: evaluation of test version. RMD Open. 2016;2:e 000214.

63. Andersson G. Using internet to provide cognitive behavior therapy. Behav. Res. Ther. 2009;47:175-80.

64. Garg S, Garg D, Turin TC, Chowdhury MF. Web-based interventions for chronic back pain: a systematic review. J Med Internet Res. 2016;18:e139.

65. Shukla H, Nair SR. Thakker DRole of telerehabilitation in patients following total knee arthroplasty: evidence from a systematic literature review and meta-analysis. J Telemed Telecare. 2017;23:339-46. 
66. Burhman M, Faltenhag S, Ström L, et al. Controlled trail of internet-based treatment with telefon support for chronic back pain. Pain. 2004;111:368-77.

67. Barak A, Klein B, Proudfoot JG. Defining internet-supported therapeutic interventions. Ann Behav Med. 2009;38:4-17.

68. Lelieveld O, Armbrust W, Geertzen J, de Graaf I, van Leeuwen MA, Sauer PJ, et al. Promoting physical activity in children with juvenile idiopathic arthritis through an internet-based program: results of a pilot randomized controlled trial. Arthritis Care Res. 2010;62:697-703.

69. Bring A, Åsenlöf P, Söderlund A. What is the comparative effectiveness of current standard treatment, against an individually tailored behavioural programme delivered either face-to face for people with acute whiplash associated disorder? A randomized controlled trial. Clin Rehabil. 2016;30:441-53.

70. Carlsson AM. Assessment of chronic pain. I. Aspects of the reliability and validity of the visual analogue scale. Pain. 1983;16:87-101.

71. Vernon $\mathrm{H}$, Mior S. The neck disability index: a study of reliability and validity. J Manip Physiol Ther. 1991;14:409-15.

72. Statistics Sweden (SCB) SSYK 2012 Standard för svensk yrkesklassificering 2012. http://www.scb.se/statistik/_publikationer/OV9999_2012A01_BR_ X70BR1201.pdf (In Swedish). (Devoloped from the ISCO-08 (International Standard Classification of Occupation 2008 http://www.ilo.org/public/ english/bureau/stat/isco/isco88/index.htm))

73. Weathers FW, Litz BT, Herman DS, Huska JA, Keane TM. The PTSD checklist $(\mathrm{PCL})$ : reliability, validity, and diagnostic utility. 9th Annual Meeting of the International Society for Traumatic Stress Studies, San Antonio, TX 1993.

74. Wilkins KC, Lang AJ, Norman SB. Synthesis of the psychometric properties of the PTSD checklist (PCL) military, civilian, and specific versions. Depress Anxiety. 2011;28:596-606.

75. Willis C, Niere KR, Hoving JL, Green S, O'Leary EF, Buchbinder R. Reproducibility and responsiveness of the whiplash disability questionnaire. Pain. 2004:110:681-8.

76. Pinfold M, Niere KR, O'Leary EF, Hoving JL, Green S, Buchbinder R. Validity and internal consistency of a whiplash-specific disability measure. Spine. 2004;29:263-8

77. Stupar M, Côté P, Beaton DE, Boyle E, Cassidy JD. A test-retest reliability study of the whiplash disability questionnaire in patients with acute whiplash-associated disorders. J Manip Physiol Ther. 2015;38:629-36.

78. Stratford P, Gill C, Westaway M, Binkley J. Assessing disability and change on individual patients: a report of a patient specific measure. Physiother Canada. 1995;47:358-63.

79. Barbero M, Moresi F, Leoni D, Gatti R, Egloff M, Falla D. Test-retest reliability of pain extent and pain location using a novel method for pain drawing analysis. Eur J Pain. 2015;19:1129-38.

80. Jacobson GP, Newman CW. The development of the dizziness handicap inventory. Arch Otolaryngol Head Neck Surg. 1990;116:424-7.

81. Yang M, Rendas-Baum R, Varon SF, Kosinski K. Validation of the headache impact test (HIT-6TM) across episodic and chronic migraine. Cephalalgia. 2010;31:357-67.

82. Bridger RS, Kjøs Johnsen SÅ, Brasher K. Psychometric properties of the cognitive failures questionnaire. Ergonomics. 2013;56:1515-24.

83. Osman A, Barrios FX, Gutierrez PM, Kopper BA, Merrifield T, Grittmann L. The pain catastrophizing scale: further psychometric evaluation with adult samples. J Behavioral Med. 2000;23:351-65.

84. Altmaier ERD, Kao C, Lehmann T, Weinstein J. Role of self-efficacy in rehabilitation outcome among chronic low back pain patients. J Counsel Psychol. 1993;36:725-33.

85. Waddell G, Newton M, Henderson I, Somerville D, Main CJ, Slade PD, et al. A fear-avoidance beliefs questionnaire $(F A B O)$ and the role of fear-avoidance beliefs in chronic low back pain and disability. Pain. 1993;52:157-68.

86. Dedering A, Borjesson T. Assessing fear-avoidance beliefs in patients with cervical radiculopathy. Physiother Res Int. 2013;18:193-202.

87. Zigmond AS, Snaith RP. The hospital anxiety and depression scale. Acta Psychiatr Scand. 1983;67:361-70.

88. Tuomi K, Ilmarinen J, Jahkola A, Katajarinne L, Tulkki A. Work ability index. Finnish Institute of Occupational Health: Helsinki; 1998. https://academic. oup.com/occmed/article/57/2/160/1584972/The-Work-Ability-Index-WAI.

89. Radkiewich P, Widerszal-Bazyl M. Psychometric properties of work ability index in the light of comparative survey study. Int Congr Ser. 2005: 1289-304.

90. de Zwart BC, Frings-Dresen MH, van Duivenbooden JC. Test-retest reliability of the work ability index questionnaire. Occup Med. 2002:52:177-81.

91. Brooks R. EuroQol: the current state of play. Health Policy. 1996;37:53-72.
92. Kamper SJ, Maher CG, Mackay G. Global rating of change scales: a review of strengths and weaknesses and considerations for design. J Manip Physiol Ther. 2009;17:163-70.

93. Siegrist JDS, Chandola T, Godin I, Marmot M, Niedhammer I, Peter R. The measurement of effort-reward imbalance at work, European comparisons. Soc Sci \& Med. 2004;58:1483-99.

94. Koopman C, Pelletier KR, Murray JF, Sharda CE, Berger ML, Turpin RS. Stanford presenteeism scale: health status and employee productivity. J Occup Environ Med. 2002:44:14-20.

95. Turpin RS, Ozminkowski RJ, Sharda CE, Collins JJ, Berger ML, Billotti GM, et al. Reliability and validity of the Stanford Presenteeism scale. J Occup Environ Med. 2004;46:1123-33.

96. Cherkin DC, Deyo RA, Street JH, Barlow W. Predicting poor outcomes for back pain seen in primary care using patients' own criteria. Spine. 1996;21:2900-7.

97. Howie JG, Heaney DJ, Maxwell M, Walker JJ. A comparison of a patient enablement instrument (PEI) against two established satisfaction scales as an outcome measure of primary care consultations. Fam Pract. 1998;15:165-71.

98. Ekberg K, Noorlind-Brage H, Dastserri M. Östgötens hälsa och miljö 2000. Folkhälsovetenskapligt Centrum Landstinget i Östergötland: Linköping; 2000. (in Swedish)

99. Peolsson A, Almkvist C, Dahlberg C, Lindqvist S, Pettersson S. Age- and sexspecific reference values of a test of neck muscle endurance. J Manip Physiol Ther. 2007;30:171-7.

100. Peolsson A, Hedlund R, Ertzgaard S, Öberg B. Intra-and inter-tester reliability and age- and sex-specific range of motion of the neck. Physiother Canada. 2000;52:233-42.

101. Hall TM, Robinson KW, Fujinawa O, Akasaka K, Pyne EA. Intertester reliability and diagnostic validity of the cervical flexion-rotation test. J Manip Physiol Ther. 2008;31(4):293-300.

102. Schneider GM, Jull G, Thomas K, Smith A, Emery C, Faris $P$, et al. Intrarater and interrater reliability of select clinical tests in patients referred for diagnostic facet joint blocks in the cervical spine. Arch Phys Med Rehabil. 2013;94:1628-34.

103. Jull GA, O'Leary SP, Falla DL. Clinical assessment of the deep cervical flexor muscles: the craniocervical flexion test. J Manip Physiol Ther. 2008:31:525-33.

104. Kammerlind A-S, Bergquist Larsson P, Ledin T, Skargren E. Reliability of clinical balance tests and subjective ratings in dizziness and disequilibrium. Adv Physiother. 2005;7:96-107.

105. Peolsson A, Hedlund R, Öberg B. Intra- and inter-tester reliability and reference values for hand strength. J Rehab Med. 2001;33:36-41.

106. Wainner RS, Fritz JM, Irrgang JJ, Boninger ML, Delitto A, Allison S. Reliability and diagnostic accuracy of the clinical examination and patient self-report measures for cervical radiculopathy. Spine. 2003;28:52-62.

107. Sjaastad O, Fredriksen TA, Pfaffenrath V. Cervicogenic headache: diagnostic criteria. Headache. 1998;38:442-5.

108. Pool JJ, Ostelo RW, Hoving JL, Bouter LM, de Vet HC. Minimal clinically important change of the neck disability index and the numerical rating scale for patients with neck pain. Spine. 2007:32:3047-51.

109. Landén Ludviggson M. Neck-specific exercise with or without a behavioural approach, or prescription of physical activity in chronic whiplash associated disorders. Linköping University Medical Dissertation 2016 No 1509.

110. Lesaffre E. Superiority, equivalence, and non-inferiority trials. Bull NYU Hosp It Dis. 2008:66:150-4. 